3. 在烷基钴配合物的热分解过程中, 其 主要气相产物的量不是固定不变的, 其比例 随反应温度的升高而发生改变. 我们测定了 相应于流出曲线最高点的温度范围中烷基钴 配合物热分解产物的组成及其比例, 如当轴 向烷基是甲基时, 甲烷与乙烷的比例随温度
的升高而减小,说明在反应开始阶段，甲基自 由基更易夺氢生成甲烷, 随之, 它们的二聚反 应越趋显著。

陈冠蓄陈慧兰张文樹唐雯霞 （南京大学化学系、分析中心、配 位化学研究所, 南京 210008)

\title{
棉花体细胞胚状体的直接发生
}

棉花是世界上最主要的纤维作物, 国内 外众多科技工作者都试图把组织培养技术用 于棉花的遗传研究和育种工作上来. 目前, 在陆地棉内愈伤组织通过细胞悬浮培养胚胎 发生形成再生植株的培养程序虽已基本建 立, 但从愈伤组织直接诱导产生体细胞胚状 体可能是更有希望的途径之一.

作者着重对柯字棉 312 在不同激素组合 的培养基上愈伤组织的诱导和体细胞胚胎发 生的能力及发育状况进行比较研究, 结果表 明从愈伤组织直接诱导产生体细胞胚状体的 程序如下:

棉籽经脱线、消毒后, 置 $0.6 \%$ 琼脂培养 基.上,在无菌、黑暗条件下培养 3-4 天,将无 菌苗的下胚轴纵切后切成长约 $0.5 \mathrm{~cm}$ 的切 段,切面朝下置于愈伤组织 MS 诱导培养基 上 $\left(\mathrm{B}_{5}\right.$ 维生素,葡萄糖 $30 \mathrm{~g} / \mathrm{L}, 2,4-\mathrm{D} 0.1 \mathrm{mg} / \mathrm{L}$, $\mathrm{KT} 0.1 \mathrm{mg} / \mathrm{L}, \mathrm{pH} 5.8), 4$ 周后进行一次 继 代培养, 2 周后转移到分化培养基上（去除
$\mathrm{NH}_{4} \mathrm{NO}_{3}$ 的 $\mathrm{MS}, \mathrm{KNO}_{3} 1.9 \mathrm{~g} / \mathrm{L}, \mathrm{B}_{5}$ 维生素 蔽萄糖 $20 \mathrm{~g} / \mathrm{L}$ ) 进行器官分化培养, 3 周后 即可出现清晰可见的胚状体, 先后共重复 4 批 45 瓶*均发育良好, 并在上述条件下可保 持 4 个月之久而无需更换培养基. 将胚状体 转移到不加任何激素的 $\mathrm{MS}+\mathrm{B}$, 维生素的 培养基上萌发后转到 $\mathrm{SH}$ 培养基上 (附加蔗 糖 $20 \mathrm{~g} / \mathrm{L}, \mathrm{pH} 7.0$ ), 1 周后就有根的形成, 在此培养基上棉苗的根、茎、叶生长较平衡, 发育良好.

此培养程序不需细胞悬浮培养过程, 可 重复性强, 易于掌握, 肧状体诱导频率高, 但 如何提高苗的分化频率, 如何使植物进一步 发育、开花结果, 尚需我们继续努力工作, 以 便为开展棉花抗枯、黄萎病突变体篮选研究 提供坚实的基础.

\section{郑传临 陈其煐}

(中国农业科学院植物保护研究所, 北京 100094)

*实验所用 $100 \mathrm{ml}$ 三角瓶, 每瓶接种 3--4 坎余纺组织.比“管”信息昆大得多. 